(C2013 the authors. Access to this work was provided by the University of Maryland, Baltimore County (UMBC) ScholarWorks@UMBC digital repository on the Maryland Shared Open Access (MD-SOAR) platform.

Please provide feedback

Please support the ScholarWorks@UMBC repository by emailing scholarworks-group@umbc.edu and telling us what having access to this work means to you and why it's important to you. Thank you. 


\section{Tactile Notifications for Ambulatory Users}

\author{
Huimin Qian \\ UMBC \\ 1000 Hilltop Circle \\ Baltimore, MD 21250, USA \\ huimin1@umbc.edu

\section{Ravi Kuber} \\ UMBC \\ 1000 Hilltop Circle \\ Baltimore, MD 21250, USA \\ rkuber@umbc.edu

\section{Andrew Sears} \\ Rochester Institute of Technology \\ 20 Lomb Memorial Drive \\ Rochester, NY 14623, USA \\ andrew.sears@rit.edu
}

\begin{abstract}
Difficulties are often associated with perceiving tactile feedback from a mobile device while ambulatory. In this paper, we describe a study conducted using multiparameter tactile icons (tactons) with a view to identifying designs to better resist the masking effects associated with walking. Our findings suggest that tactons encoded with longer durations $(800 \mathrm{~ms})$ or those with stronger intensities (Amplitude: $2.1 \mathrm{~g}$

Frequency: $255 \mathrm{~Hz}$ ) offer promise to individuals on-themove. In terms of future work, we aim to identify ways to reduce the recognition time and the levels of cognitive workload experienced when resolving multiparameter tactons, to augment the human-mobile interaction experience.
\end{abstract}

\section{Author Keywords}

Tactile Interfaces;

\section{ACM Classification Keywords}

H.5.2. User Interfaces: Haptic I/O.

\section{General Terms}

Human Factors

\section{Introduction}

Copyright is held by the author/owner(s)

CHI 2013 Extended Abstracts, April 27-May 2, 2013, Paris, France. ACM 978-1-4503-1952-2/13/04
Tactile feedback can play a vital role in mobile interactions, alerting the user to the presence of a notification when the visual or auditory channels are 
occupied, or under conditions when discretion may be required (e.g. when in a meeting). However, research suggests vibrations presented via a mobile device are often missed while ambulatory $[1,6,8,10]$, which can cause difficulties, especially if the notification requires urgent action from the user. Problems can be attributed in part to the following factors:

- Mobile hardware. Mobile devices are known to be limited in the range and intensity of tactile feedback that can be presented, due to the tactile actuators embedded within the hardware [9].

- Location where the stimulus is presented. Individuals often carry phones in their pocket or affix devices to their waist. As the sensitivity, acuity, and magnitude of tactile sensations vary substantially as a function of the location on the body [5], challenges may be faced resolving cues. Furthermore, the tactile signal may also be attenuated due to the clothing barrier between the mobile device and the user's skin.

- Impact of walking. If the mobile device is carried in the trouser pocket, the varying positions of the leg affect how the mobile phone is pressed against the thigh by the pocket, providing closer contact in some parts of the gait cycle, thereby impacting the interaction [10].

- Attentional demands. Vibrotactile perception sensitivity diminishes owing to limited attentiveness and inadequate cognitive resources [1]. Dividing attention between the environment and passively monitoring the phone may prove challenging when walking, as the user needs to focus on following the route and identifying obstacles which may impede the journey.
Research has shown that parameters of touch (e.g. amplitude modulation, frequency, waveform, spatial location) can be manipulated to develop a range of effects (tactons) that can be presented via tactile displays $[3,5]$. Studies have been conducted to identify the impact of tactons under both controlled [2], and inhospitable conditions [3]. In order to examine the impact of distracters on tactile feedback, Oakley and Park [11] evaluated tactons under three conditions (transcription, mouse-based data-entry, and walking along a corridor). Findings showed that recognition accuracy significantly reduced between $5 \%$ and $20 \%$ when distracters were present.

In order to extend previous work, we have conducted a study specifically focusing on the efficacy of perceiving multi-parameter tactons when ambulatory, with a view to identifying tactile parameters and designs of these parameters, which can be identified when the user is on-the-move. We aim to better support interface designers when developing cues to resist the effects of being in motion.

\section{Related Work}

Studies have examined the impact of walking on tactile perception. Martinsson [10] found that $29 \%$ of participants were unable to detect a single vibration, while a further $29 \%$ could recognize less than half of the tactile stimuli presented. Findings from Jirattigalachote et al. [6] revealed tactile identification accuracy was reduced from $96.6 \%$ when standing to $84.7 \%$ when walking. Baek et al. [1] presented vibrotactile stimuli to participants via a mobile device while they performed routine activities on a sidewalk, subway, or bus. The researchers determined that the vibrotactile perception rate when using a mobile phone 


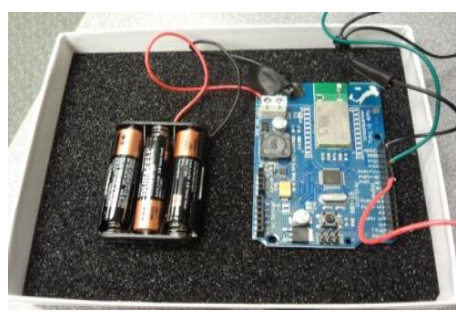

Figure 1. Prototype to distribute tactile feedback when using mobile device.

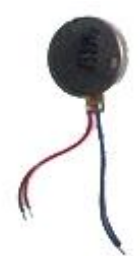

Figure 2. Pancake style motor to present tactile feedback $(3.4 \mathrm{~mm} \times 10.0 \mathrm{~mm})[12]$

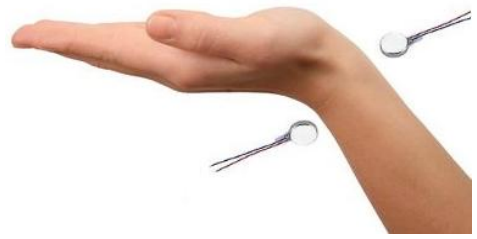

Figure 3. Presentation of tactile feedback to the volar and dorsal sites. was highest at $190 \mathrm{~Hz}$ and lowest at $150 \mathrm{~Hz}$. Karuei et al. [8] found improvements in detection odds and reductions in reaction time when stronger intensities were presented. The researchers identified that walking significantly reduced the likelihood of detecting a vibration and increased the reaction time.

While findings from these studies provide a valuable reference for tactile design when users are ambulatory, the tactons presented are simple in design, often using a limited number of parameters to foster discernible effects. Our research has focused on the feasibility of perceiving and interpreting four parameter tactons. We aim to widen the potential range of tactons which can be developed, by manipulating tactile parameters and combining them to form unique effects.

\section{Method}

The study was designed to examine the ways in which multi-parameter tactons can be designed to better resist the masking effects of walking.

Twenty volunteers (aged 18-29) were recruited. All participants reported normal levels of both tactile and auditory perception. The research was conducted using an off-the-shelf key-press mobile telephone (Nokia N95). This was selected as it represented a common mobile technology often used by individuals in the real world. The phone was affixed to the participant's waist using a cotton holder attached to a belt. In order to spatially distribute tactile feedback, a prototype was developed using Arduino technology (Figure 1) and two pancake motors [12] (Figure 2). These motors were selected as they are known to be simple to control and can produce vibrations on the skin that are readily perceptible [7]. While the motors were wired to the
Arduino controller, Bluetooth was used to communicate between the mobile device and the controller.

Participants were presented with tactons while either stationary or walking. The tactons were encoded using parameters and values derived from our earlier studies $[13,14]$. Tactons were designed to be long or short in duration ( $800 \mathrm{~ms}$ and $200 \mathrm{~ms}$ ) and intervals between presentation of feedback ( $800 \mathrm{~ms}$ and $200 \mathrm{~ms}$ ), and strong or weak in intensity (Amplitude: $2.1 \mathrm{~g}$ and Frequency: $255 \mathrm{~Hz}$, and Amplitude: $0.9 \mathrm{~g}$ and

Frequency: $153 \mathrm{~Hz}$ ). Tactons were presented at one of two locations on the wrist, following guidance from Chen et al. [4] (Figure 3). These included the volar (same side as palm) and dorsal side. Vibration actuators were affixed to the dominant arm using medical tape. The wrists were chosen to present tactile information, as in our pilot studies, participants had suggested that they would eventually prefer tactile signals to be integrated with accessories such as wristwatches. Effects were repeated up to three times to form tactile rhythms, resulting in total durations of 1$5 s$.

\section{Hypotheses}

$\mathrm{H} 1$ : The rate of identification for four parameter tactons will be greater in the stationary condition compared when walking.

$\mathrm{H} 2$ : Four parameter tactons encoded with stronger intensities will be more perceivable than weaker intensities, under both stationary and walking conditions. The parameter of intensity was focused upon, as in our earlier study [14], it had been found to better resist the impact of ambient sounds compared with other parameters. 


\section{Table 2: Rate of}

\section{Identification when}

\section{Stationary and Walking by} Set

\begin{tabular}{|c|c|c|}
\hline Set & $\begin{array}{c}\text { Rate of ID } \\
\text { Stationary }\end{array}$ & $\begin{array}{c}\text { Rate of ID } \\
\text { Walking }\end{array}$ \\
\hline $\mathbf{1}$ & $100.0 \%$ & $100.0 \%$ \\
\hline $\mathbf{2}$ & $100.0 \%$ & $100.0 \%$ \\
\hline $\mathbf{3}$ & $26.5 \%$ & $0.0 \%$ \\
\hline $\mathbf{4}$ & $51.7 \%$ & $8.3 \%$ \\
\hline $\mathbf{5}$ & $100.0 \%$ & $93.4 \%$ \\
\hline $\mathbf{6}$ & $100.0 \%$ & $91.7 \%$ \\
\hline $\mathbf{7}$ & $15.0 \%$ & $0.0 \%$ \\
\hline $\mathbf{8}$ & $0.0 \%$ & $0.0 \%$ \\
\hline $\mathbf{9}$ & $100.0 \%$ & $98.4 \%$ \\
\hline $\mathbf{1 0}$ & $86.7 \%$ & $66.7 \%$ \\
\hline $\mathbf{1 1}$ & $0.0 \%$ & $0.0 \%$ \\
\hline $\mathbf{1 2}$ & $10.0 \%$ & $0.0 \%$ \\
\hline $\mathbf{1 3}$ & $100.0 \%$ & $88.4 \%$ \\
\hline $\mathbf{1 4}$ & $73.4 \%$ & $38.4 \%$ \\
\hline $\mathbf{1 5}$ & $0.0 \%$ & $0.0 \%$ \\
\hline $\mathbf{1 6}$ & $0.0 \%$ & $0.0 \%$ \\
\hline \multicolumn{3}{|c}{} \\
\hline
\end{tabular}

\section{Training and Main Procedure}

To train participants, a similar technique was used to a previous study [14]. One-parameter tactons were introduced in sequence (duration long, duration short, interval long, interval short, intensity strong, intensity weak, spatial location volar, spatial location dorsal). Participants were asked to describe the parameter presented and its respective design (e.g. strong/weak, long/short etc.). Once comfortable with perceiving one parameter tactons, multi-parameter tactons were then introduced. The period of training lasted for approximately 20 minutes.

Table 1: Design of 16 Sets of Tactons

\begin{tabular}{|c|c|c|c|c|}
\hline Set & Duration & Interval & Intensity & Location \\
\hline $\mathbf{1}$ & Long & Long & Strong & Volar \\
\hline $\mathbf{2}$ & Long & Long & Strong & Dorsal \\
\hline $\mathbf{3}$ & Long & Long & Weak & Volar \\
\hline $\mathbf{4}$ & Long & Long & Weak & Dorsal \\
\hline $\mathbf{5}$ & Long & Short & Strong & Volar \\
\hline $\mathbf{6}$ & Long & Short & Strong & Dorsal \\
\hline $\mathbf{7}$ & Long & Short & Weak & Volar \\
\hline $\mathbf{8}$ & Long & Short & Weak & Dorsal \\
\hline $\mathbf{9}$ & Short & Long & Strong & Volar \\
\hline $\mathbf{1 0}$ & Short & Long & Strong & Dorsal \\
\hline $\mathbf{1 1}$ & Short & Long & Weak & Volar \\
\hline $\mathbf{1 2}$ & Short & Long & Weak & Dorsal \\
\hline $\mathbf{1 3}$ & Short & Short & Strong & Volar \\
\hline $\mathbf{1 4}$ & Short & Short & Strong & Dorsal \\
\hline $\mathbf{1 5}$ & Short & Short & Weak & Volar \\
\hline $\mathbf{1 6}$ & Short & Short & Weak & Dorsal \\
\hline
\end{tabular}

Participants were presented with two conditions; perceiving tactons while stationary (standing upright), and while walking at an average pace along a flat indoor pathway within a university building. 16 tactons were developed, each with a unique design (Table 1). Tacton were presented to participants one at a time in a randomized order. Participants were asked to identify the parameters encoded within each tacton. They were able to replay each tacton as many times as necessary until a judgment could be made. Participants were then asked to describe the design of the tacton to the experimenter. The time taken was then recorded. Each of the 16 tactons was presented three times in total. Participants completed both conditions, which were also presented in a randomized order.

Questionnaires were administered after each condition to identify levels of cognitive workload and confidence in perceiving tactons while stationary and while in motion.

\section{Results and Discussion}

\section{Rate of Identification by Condition}

Tables 2 and 3 display results for each of the sixteen tacton sets. A one-way ANOVA performed revealed the presence of a significant effect for both recognition accuracy $(F(15,304)=7.101, p<0.001)$ and time taken $(F(15,304)=181.632, p<0.001)$. Post-hoc analysis (Bonferroni corrected) was performed on the data for recognition rate. Findings confirmed that tacton sets $1,2,5,6,9$ and 13 , all of which were encoded with stronger intensities, were identified with greater levels of accuracy when stationary (M:100.0\%, SD:0.0\%, $\mathrm{p}<0.001$ ) compared with sets $3,4,7,8,11,12,15$ and 16 , which were all encoded with weaker intensities (M: $12.9 \%$, SD: $12.8 \%$ ). Similar results were also obtained when walking (Strong intensity: M: 95.3\%, SD: 4.9\%, Weak intensity: M: $1.0 \%$, SD: $2.3 \%, \mathrm{p}<0.001$ ), highlighting the importance of encoding tactons with stronger levels of intensity irrespective of the usage condition (i.e., walking or stationary). 
Table 3: Task Time when Stationary and Walking by Set

\begin{tabular}{|c|c|c|}
\hline Set & $\begin{array}{c}\text { Rate of ID } \\
\text { Stationary }\end{array}$ & $\begin{array}{c}\text { Rate of ID } \\
\text { Walking }\end{array}$ \\
\hline $\mathbf{1}$ & $5.3 \mathrm{~s}(2.5 \mathrm{~s})$ & $9.6 \mathrm{~s}(1.8 \mathrm{~s})$ \\
\hline $\mathbf{2}$ & $5.3 \mathrm{~s}(2.4 \mathrm{~s})$ & $9.7 \mathrm{~s}(1.9 \mathrm{~s})$ \\
\hline $\mathbf{3}$ & $9.0 \mathrm{~s}(3.1 \mathrm{~s})$ & $15.2 \mathrm{~s}(2.9 \mathrm{~s})$ \\
\hline $\mathbf{4}$ & $9.0 \mathrm{~s}(2.9 \mathrm{~s})$ & $14.9 \mathrm{~s}(2.8 \mathrm{~s})$ \\
\hline $\mathbf{5}$ & $5.8 \mathrm{~s}(2.4 \mathrm{~s})$ & $10.9 \mathrm{~s}(2.1 \mathrm{~s})$ \\
\hline $\mathbf{6}$ & $5.6 \mathrm{~s}(2.6 \mathrm{~s})$ & $10.9 \mathrm{~s}(2.2 \mathrm{~s})$ \\
\hline $\mathbf{7}$ & $8.5 \mathrm{~s}(2.8 \mathrm{~s})$ & $14.5 \mathrm{~s}(3.1 \mathrm{~s})$ \\
\hline $\mathbf{8}$ & $8.4 \mathrm{~s}(2.8 \mathrm{~s})$ & $14.7 \mathrm{~s}(3.3 \mathrm{~s})$ \\
\hline $\mathbf{9}$ & $5.1 \mathrm{~s}(2.4 \mathrm{~s})$ & $9.7 \mathrm{~s}(2.0 \mathrm{~s})$ \\
\hline $\mathbf{1 0}$ & $6.0 \mathrm{~s}(2.9 \mathrm{~s})$ & $12.0 \mathrm{~s}(2.1 \mathrm{~s})$ \\
\hline $\mathbf{1 1}$ & $8.5 \mathrm{~s}(2.5 \mathrm{~s})$ & $14.7 \mathrm{~s}(3.0 \mathrm{~s})$ \\
\hline $\mathbf{1 2}$ & $8.6 \mathrm{~s}(2.7 \mathrm{~s})$ & $15.3 \mathrm{~s}(3.2 \mathrm{~s})$ \\
\hline $\mathbf{1 3}$ & $5.8 \mathrm{~s}(2.4 \mathrm{~s})$ & $10.7 \mathrm{~s}(1.9 \mathrm{~s})$ \\
\hline $\mathbf{1 4}$ & $5.8 \mathrm{~s}(2.4 \mathrm{~s})$ & $10.8 \mathrm{~s}(2.0 \mathrm{~s})$ \\
\hline $\mathbf{1 5}$ & $8.5 \mathrm{~s}(2.8 \mathrm{~s})$ & $14.6 \mathrm{~s}(2.9 \mathrm{~s})$ \\
\hline $\mathbf{1 6}$ & $8.4 \mathrm{~s}(2.8 \mathrm{~s})$ & $14.8 \mathrm{~s}(3.1 \mathrm{~s})$ \\
\hline
\end{tabular}

\section{Comparison between Conditions}

A repeated measures ANOVA showed that tactons could be most accurately identified when stationary ( $M$ : $54.0 \%$, SD: $46.2 \%$ ), compared to when walking ( $M$ 42.8\%, SD: $46.7 \%)(F(1,15)=88.607, p<0.001)$. Participants spent significantly longer responding to tactile effects while walking (M: $12.7 \mathrm{~s}, \mathrm{SD}: 3.3 \mathrm{~s})$ compared to being stationary (M: 7.1s, SD: $3.0 \mathrm{~s}$ ) $(F(1,15)=1886.693, p<0.001)$. Greater levels of cognitive workload were expended when participants attempted to interpret tactons while in motion, compared to when stationary (Percentage change: $\mathrm{M}$ : $46.1 \%$, SD: $12.1 \%)(F(1,19)=58.731, \mathrm{p}<0.001)$.

Recognition rates and time taken to perceive each parameter with associated value (termed 'design') are shown in Tables 4 and 5 . The results suggest the benefits of encoding tactons with stronger intensities, and using longer durations. A mixed model analysis performed on the data revealed significant effects of recognition rate $(F(1,7)=198.763, p<0.001)$ and time taken between the two conditions $(F(1,7)=1181.815$, $\mathrm{p}<0.001$ ). Post-hoc analysis (Bonferroni corrected) suggested that tactons encoded with short durations (Percentage change: M: $21.1 \%$, SD: $47.8 \%, p<0.001$ ) were impacted more significantly when walking compared with tactons encoded with long durations (Percentage change: M: $20.4 \%$, SD: $48.2 \%$ ). Tactons encoded with longer intervals (Percentage change: $M$ : $21.3 \%$, SD: $52.3 \%, p<0.001$ ) were more affected when walking than those encoded with shorter intervals (Percentage change: M: $19.4 \%$, SD: $87.8 \%$ ). Findings revealed that time required to identify tactons encoded with strong intensities was impacted more significantly when walking than those encoded with weaker intensities (Percentage change: Strong Intensity- M:
$88.8 \%$, SD: $22.5 \%$; Weak Intensity - M: $72.3 \%$, SD: $7.4 \%, \mathrm{p}<0.001)$. Although findings revealed tactons presented at the volar locations to be recognized with greater levels of accuracy compared with presentation at dorsal sites, no effect could be detected.

The results suggest that $\mathrm{H} 1$ can be accepted, as the rate of tactile identification was found to be higher when stationary compared to walking. When stationary, participants were able to direct their attention towards perceiving and interpreting feedback without needing to deal with distracters from the wider environment. The process of resolving tactons when walking was found to be more time consuming and attention-demanding, which participants suggested impacted their ability to deal with vibrations presented via their personal mobile devices when performing real world tasks (e.g. when running to a lecture with the phone in the trouser pocket, in the presence of corridor noise from students).

Tactons encoded with stronger intensities were found to more effectively resist the masking effects of walking compared with weaker intensities, enabling us to accept $\mathrm{H} 2$. However, a greater percentage change in task time was observed for tactons encoded with stronger intensities, suggesting that when ambulatory, additional cognitive resources are needed to maintain the same level of recognition accuracy for the most perceivable cues as when stationary.

It has been acknowledged that the motors such as the ones used in this study, are known to have limited power-to-mass ratios, and problems can be faced controlling frequency and amplitude of vibrations independently, limiting the range of distinctive signals 


\section{Table 4: Identification when Stationary and Walking by Tacton Design}

\begin{tabular}{|c|c|c|}
\hline Design & $\begin{array}{c}\text { Rate of ID } \\
\text { Stationary }\end{array}$ & $\begin{array}{c}\text { Rate of ID } \\
\text { Walking }\end{array}$ \\
\hline $\begin{array}{c}\text { Duration } \\
\text {-Long }\end{array}$ & $61.8 \%$ & $49.2 \%$ \\
\hline $\begin{array}{c}\text { Duration } \\
\text { - Short }\end{array}$ & $46.3 \%$ & $36.6 \%$ \\
\hline $\begin{array}{c}\text { Interval- } \\
\text { Long }\end{array}$ & $59.5 \%$ & $46.8 \%$ \\
\hline $\begin{array}{c}\text { Interval } \\
\text {-Short }\end{array}$ & $48.6 \%$ & $39.2 \%$ \\
\hline $\begin{array}{c}\text { Intensity } \\
\text {-Strong }\end{array}$ & $95.1 \%$ & $84.7 \%$ \\
\hline $\begin{array}{c}\text { Intensity } \\
\text { Weak }\end{array}$ & $13.0 \%$ & $1.0 \%$ \\
\hline $\begin{array}{c}\text { Location } \\
\text { - Volar }\end{array}$ & $55.1 \%$ & $47.6 \%$ \\
\hline $\begin{array}{c}\text { Location } \\
\text { - Dorsal }\end{array}$ & $52.7 \%$ & $38.2 \%$ \\
\hline
\end{tabular}

\section{Table 5: Task Time Taken} when Stationary and Walking by Tacton Design

\begin{tabular}{|c|c|c|}
\hline Design & $\begin{array}{c}\text { Task Time } \\
\text { Stationary }\end{array}$ & $\begin{array}{c}\text { Task Time } \\
\text { Walking }\end{array}$ \\
\hline $\begin{array}{c}\text { Duration } \\
\text {-Long }\end{array}$ & $7.1 \mathrm{~s}$ & $12.6 \mathrm{~s}$ \\
\hline $\begin{array}{c}\text { Duration } \\
\text { - Short }\end{array}$ & $7.1 \mathrm{~s}$ & $12.8 \mathrm{~s}$ \\
\hline $\begin{array}{c}\text { Interval- } \\
\text { Long }\end{array}$ & $7.1 \mathrm{~s}$ & $12.6 \mathrm{~s}$ \\
\hline $\begin{array}{c}\text { Interval } \\
\text {-Short }\end{array}$ & $7.1 \mathrm{~s}$ & $12.7 \mathrm{~s}$ \\
\hline $\begin{array}{c}\text { Intensity } \\
\text {-Strong }\end{array}$ & $5.6 \mathrm{~s}$ & $10.6 \mathrm{~s}$ \\
\hline $\begin{array}{c}\text { Intensity } \\
\text { Weak }\end{array}$ & $8.6 \mathrm{~s}$ & $14.8 \mathrm{~s}$ \\
\hline $\begin{array}{c}\text { Location } \\
\text { - Volar }\end{array}$ & $7.1 \mathrm{~s}$ & $12.5 \mathrm{~s}$ \\
\hline $\begin{array}{c}\text { Location } \\
\text { - Dorsal }\end{array}$ & $7.1 \mathrm{~s}$ & $12.9 \mathrm{~s}$ \\
\hline
\end{tabular}

available [7]. Further studies would aim to examine the efficacy of using alternative actuation technologies.

\section{Conclusions and Future Work}

When designing user interfaces for ambulatory users, our results suggest that encoding tactons with stronger intensities or with longer durations offer the most potential for conveying information to the user, regardless of whether walking or stationary. However, time and cognitive effort will be taken to resolve these cues. Future work will be conducted to work towards addressing these areas.

Due to the controlled nature of the study, participants were not subjected to obstacles or interruptions which they may ordinarily face when walking in a real-world environment. As the next step in the research, we aim to conduct a longitudinal study to better understand the challenges faced under more natural surroundings. As part of the study, participants would be asked to maintain diaries, highlighting details of other tasks performed when the notification was presented (e.g. while typing an email) along with the contextual and environmental distractors (e.g. sound of TV in background) faced when perceiving tactile feedback. Research would be performed to ensure that tactons can be designed to better resist these distractions.

\section{References}

[1] Baek, Y., Myung, R. and Yim, J. Have you ever missed a call while moving? The Optimal Vibration Frequency for Perception in Mobile Environments. In Proc. ICAIS 2006.

[2] Brown, L.M., Brewster, S.A. and Purchase, H.C. Multidimensional tactons for non-visual information presentation in mobile devices. In Proc. MobileHCI 2006, 231-238.
[3] Brewster, S.A., Chohan, F. and Brown, L.M. Tactile feedback for mobile interactions. In Proc. CHI 2007, 159-162.

[4] Chen, H.Y. et al. Tactor localization at the wrist. In Proc. Eurohaptics 2008, 209-218.

[5] Hoggan, E. and Brewster, S.A. New parameters for tacton design. Ext. Abstracts CHI 2007, 2417-2422.

[6] Jirattigalachote, W., Shull P.B. and Cutkosky, M.R. Virtual pebble: A haptic state display for pedestrians. In Proc. RO-MAN 2011, 401-406.

[7] Jones, L.A. and Sarter, N.B. Tactile displays: Guidance for their design and application. Human Factors, 50 (1).

[8] Karuei, I. et al. Detecting vibrations across the body in mobile contexts. In Proc. CHI 2011, 32673276.

[9] MacLean, K.E. Using haptics for mobile information display. In Proc. of PERMID Workshop 2008, 175-179.

[10] Martinsson, M. 2011. Detection of mobile phone vibrations during walking. Masters Thesis, University of Lund, Sweden.

[11] Oakley, I. and Park, J. Did you feel something? Distracter tasks and the recognition of vibrotactile cues. Interacting with Computers, 2008, 354-363.

[12] Precision Microdrives, 2012 [b]. Product Data Sheet. Technical Report, 310-113, 1-7.

[13] Qian, H., Kuber, R. and Sears, A. 2011. Towards Developing Perceivable Tactile Feedback for Mobile Devices. International Journal of Human Computer Studies 69, 705-719.

[14] Qian, H., Kuber, R. and Sears, A. 2013. Determining the Efficacy of Multi-Parameter Tactons in the Presence of Real-world and Simulated Audio Distractors. Submitted to journal. 